\title{
Denying the severity of mental health problems to deny rights to the homeless
}

\author{
Caroline Hunter* \\ University of Manchester
}

\begin{abstract}
Summary
This paper looks at the way decisions are made by local authorities under Housing Act 1996, Part 7, in relation to single homeless people who claim to be vulnerable due to mental health problems. The Act provides no definition of vulnerability, and there has been a plethora of cases which have examined its meaning. Through consideration of reported court cases the paper shows how local authorities have tried to limit their duties to those with mental health problems and how the courts have generally been willing to uphold such an approach. It then considers how authorities use medical evidence in making these decisions and in particular the role of the independent firm NowMedical. The most recent case law has begun to limit the way in which the decisions of NowMedical can be seen to override the evidence from applicants' own medical advisers.
\end{abstract}

Keywords: mental health, homelessness, medical evidence.

\section{Introduction}

Ever since the introduction of statutory protection for the homeless in 1977 to be eligible for assistance applicants have had to satisfy a local authority that they pass a number of hurdles in order to obtain full assistance under the act. If they overcome the hurdles, the local authority must secure that the applicant and his family is housed (Watchman and Robson, 1981). The current law is now contained in the Housing Act 1996, part 7 (for a detailed account see, Arden et al 2006). Although the duty towards the homeless is not to provide permanent housing, being accepted as a homeless person to whom the full duty is owed is an important route into social rented housing. Homeless persons must be afforded some priority in local authority allocation schemes (see Housing Act ('H.A. ') 1996, s.167).

The hurdles imposed by the Act include a requirement that the applicant is in priority need. The definition of priority need in the 1977 Act which has persisted through to the current legislation was based on a Circular first issued jointly by the then 
Departments of Environment and Health and Social Security in 1974. The current statutory provision is to be found in H.A. 1996, s.189 which provides that those with a priority need for accommodation include:

(c) a person who is vulnerable as a result of old age, mental illness or handicap or physical disability or other special reason, or with whom such a person resides or might reasonably be expected to reside

For single people who become homeless, unless they can show that they fall within this definition, there is no statutory obligation to provide assistance. The focus of this article is on those with mental health problems who are rejected on the basis that they are not vulnerable.

There has in the last five years or so been pressure on authorities from central Government to bring down the numbers of homelessness acceptances. This pressure has been quite effective. There were 17,230 acceptances in England, during the first quarter of 2007, 17 per cent lower than in the same period in 2006, and the lowest quarterly value since the early 1980s (DCLG, 2007a). This downward trend was continued into the second quarter, where the numbers were lower still (DCLG, 2007b). Just over 20 percent of those who were rejected in 2006-07 were rejected on the basis that they were not in priority need (DCLG, 2007c). Of those who were accepted in $2006-07,7 \%$ were found to be in priority need because of vulnerability due to mental health (DCLG, 2007d).

In order to understand how the process of exclusion from assistance for the mentally ill has developed, the paper will first examine the definition of vulnerability as it has emerged in case law, and in particular how that has been applied to those who have mental health problems. The paper then goes on to consider how authorities make decisions and operate gate-keeping in the context of the medical evidence they obtain. In particular it considers the role of NowMedical (a private company from which local authorities can purchase medical advice) and the response of the courts to this medical advice.

\section{Definition of vulnerability}

The 1996 Act provides no further assistance as to what is meant by 'vulnerable' but there has been a number of cases where it has been considered by the courts. The leading case is that of R. v Camden LBC, ex p Pereira (1998) 31 HLR 317, CA, which stated that vulnerability means an applicant being 'less able to fend for himself than an ordinary homeless person so that injury or detriment to him will result where a less vulnerable man will be able to cope without harmful effects.' The starting position therefore is that the applicant has become or will become street homeless, it does not turn (as had been suggested in some earlier cases) on his/her ability to fend for him/herself while still housed: Osmani v. Camden L.B.C. [2004] EWCA Civ 1775; [2005] HLR 22.

What the case law has also emphasised is that the decision is one for the local authority and is necessarily imprecise, and in so doing has sought to discourage appeals (under the statutory procedure to the county court) against such decisions. In Osmani Auld LJ said at para 38:

Given that each authority is charged with local application of a national scheme of priorities but against its own burden of homeless persons and finite resources, such decisions are often likely to be highly judgmental. In the context of 
balancing the priorities of such persons a local housing authority is likely to be better placed in most instances for making such a judgment.

\section{Are those with mental health problems vulnerable?}

What the Periera test establishes is that when making a decision about vulnerability, the authority must look forward to the future, i.e. it is an assessment of risk. An attempt to quantify this risk, however, failed in Griffin v. Westminster C.C. [2004] EWCA Civ 108; [2004] HLR 32. In that case it was agreed that the applicant suffered from depression - the relevant letter stated that 'I acknowledge that you suffer from depression.' It continued, however, that 'I am not satisfied that this is severe enough to conclude that you would be less able to fend for yourself when homeless so that injury or detriment would occur more than an ordinary person.'

Drawing on the then Code of Guidance published by the Government, the applicant argued that the test should be one that it would be 'likely' that the homeless person would suffer injury or detriment. This was rejected - the test is simply one of 'would' the applicant when homeless, because of his reactive depression, be less well able to fend for himself so that he 'would' suffer injury or detriment. The Court continued (para. 16):

Detriment in that context might include, in a particular case, a significantly increased risk of suicide or of developing some serious ailment. That would not have to be measured in percentage terms, and in my judgement the court should do nothing to add to the guidance already given by the statute and by Periera.

Notwithstanding the rejection of a 'likelihood' test we can already see the court adding their own i.e. 'significantly increased risk.' Essentially it has been left to the decision-making authority to assess the risk and place its own judgement without any statement as to how great that risk should be. Given the uncertainties of future prognosis it seems to give authorities a route simply to say the risk is not high enough.

The assessment is to be by comparison with the 'ordinary homeless person.' In the case of Osmani, we can see how this risk assessment and comparison with the nonvulnerable come together. Mr Osmani was a refugee from Kosovo. He had been imprisoned and beaten in prison in Kosovo and according to the judgment "was deeply disturbed by the experiences, and following his release, spent several weeks as an inpatient at a psychiatric hospital in Kosovo.' He escaped to the UK, where his wife later joined him, and they eventually applied as homeless.

In support of his contention that he was vulnerable, evidence was put to the local authority about Mr Osmani's current psychiatric condition. His GP stated that $\mathrm{Mr}$ Osmani suffered from depression and post-traumatic stress, but stated that he was fully functional save for language problems. His report continued:

...His continued homeless situation is persisting in exacerbating all of the above in my opinion. It is increasing his level of stress which risks making him more unwell and leading to a deterioration in his depressive symptoms and post-traumatic stress...To leave this man without a secure place to live puts this man's mental health at serious risk.

He stated that the prognosis was 'Poor if he does not find or is not found suitable accommodation in the very near future.' 
A report was also received from a therapist at a specialist support centre for Bosnian refugees. This stated that Mr Osmani had a large number of symptoms of PTSD and Major Depressive Disorder. The reports were sent to the authority's medical assessment officer, a psychologist, who noted a number of contradictions between the reports - in particular as to Mr Osmani's level of functioning. He concluded that $\mathrm{Mr}$ Osmani was not vulnerable. His report stated that:

Prognosis says 'poor if he does not find a flat or a flat is not found for him'. So whether detriment and injury would definitely result to him is somewhat dubious, as I feel that he is not less capable of fending for himself on medical grounds.

So here we have a test applied by the authority's medical officer of whether injury or detriment would 'definitely' result. This assessment was passed on to the reviewing officer, who accepted that Mr Osmani had PTSD and MDD. She rejected, however, his claim to be vulnerable, concluding that:

It is apparent that there must be some infirmity or characteristic of the applicant, which marks out their vulnerability from that of other applicants. I am of the view that there were no such circumstances in your [case].

This was upheld on appeal. Although there was no doubt that Mr Osmani had a depressive illness, it was not such as to prevent him from fending for himself. The reviewing officer had correctly carried out the task of 'assessing the future risk to those capabilities if and when he was to become homeless.' The judge continued:

Would his condition deteriorate such that he would not be able to do anything about his homelessness unaided and/or to harm him more than it would an 'ordinary homeless person'? In my view, the reviewing officer's conclusion that the risk was not such as to make him vulnerable for either of those purposes was, for the reason she gave, one that was reasonably open to her.

The judge does not deal with the level of risk that is necessary, nor did the reviewing officer do anything other than assert that she was of the view that Mr Osmani was no less able to fend for himself when homeless than his peers so that injury or detriment 'will not result.'

The nature of the peers to be used in this comparison is indicated in $R$ (Yeter) $v$. Enfield L.B.C. [2002] EWHC 2185, another case involving a refugee suffering from depression. The judge in considering whether the authority had applied the vulnerability test correctly stated:

Comparison is to be made with an ordinary person who is homeless, and such would be expected to endure by virtue of the homelessness some features of depression. That depression is likely to be exacerbated if the homelessness continues.

So it is not that homelessness will not exacerbate mental health problems, rather it is that this will happen to everyone, and is therefore to be discounted.

In the case of Kruja v. Enfield L.B.C. [2005] H.L.R. 13 a family of Kosovan refugees were considered. The decision letter, which the Court of Appeal concluded there was no basis for overturning, stated that:

The medical evidence suggests strong symptoms of post traumatic stress (in Dritan's case) and depression (in Remzi's case) linked to your previous 
experiences. There are unfortunately, very common conditions in many people who approach this service for assistance.

The conclusion which can be taken from this, is that depression and PTSD are the lot of the ordinary homeless person. So it would seem that depression per se is not sufficient to make an applicant vulnerable as this is one of the normal vicissitudes of homelessness and a risk to be borne by the homeless without assistance from the state.

One feature in the cases which seems to mark out a point of differentiation is that of suicidal ideation. In Osmani, the therapist referred to some suicidal ideation, although acknowledged by the authority, this was dismissed in the following terms:

I noted that you that you do not have any history [of] suicide attempts and you do not appear to have any active plans. I noted that no psychotic features were identified.

In Yeter no suicidal ideation was found. This is in marked contrast to R. v. Newham LBC, ex p. Lumley (2001) 33 HLR 11. The last evidence received by the authority (albeit after the court proceedings had commenced, but consistent with earlier evidence from the applicant's GP) was that Mr Lumley was suffering from 'a depressive illness of marked degree associated with a high risk of suicide.' Mr Lumley had in fact attempted suicide fewer than 3 years before.

The judge in this case was clearly sympathetic to Mr Lumley's position. He stated:

It must not be forgotten, too, that if [the psychiatrist's] diagnosis turns out to be correct, the effect of the withdrawal of accommodation in Mr Lumley's case may not merely be the loss of a temporary home: it may be the loss of a human life.

In both the later cases of Yeter and Osmani lip-service is paid to the decision in Lumley, but in neither are the circumstances of the applicant felt to be sufficiently severe to warrant the quashing of the local authority decision. Further in the more recent case of Bellouti v. Wandsworth L.B.C. [2005] H.L.R. 46, where there was conflicting evidence about whether the suicide would be acted out, a decision of no vulnerability was upheld.

As noted above, in Osmani the Court of Appeal emphasised the role of the local authority. This approach has been further underlined in subsequent cases. The limited role of the courts in overturning the gate-keeping decisions of local authorities was stressed in Kruja, where the first instance judge had decided that the decision of the local authority was perverse. Allowing an appeal, the Court of Appeal admitted that:

Some might consider the decision a harsh one. Some decision-makers might have arrived at a different conclusion. It is elementary that matters of that kind were not for the judge nor are they for us.

\section{On what expertise is the gate-keeping carried out?}

The Act is framed in such a way that it is not for the applicant to 'prove' their case rather the local authority has to satisfy itself as to whether the applicant qualifies (see H.A. 1996, s.184). The starting point for decision-making is that if an applicant provides his/her own evidence and the local authority has no basis for refuting it then it must be accepted (see $R$ v. Bath C.C., ex p Sagermano (1984) 17 HLR 94, a case of 
learning impairment). This is not to say that an applicant will be accepted as vulnerable, however. In some circumstances authorities are happy to effectively accept the medical diagnosis, but then reach their own conclusion about the level of risk that serves to deny vulnerability (see e.g. Osmani, discussed above).

In most cases, however, the local authority seek to provide their own medical evidence, rather than simply accepting that put to them by the applicant. This can lead to a 'battle' between the experts on each side.

This was shown in the case of Bellouti, where there were a series of reports and then responses from the applicant's GP and psychologist and the authority's medical adviser. In that case the evidence from the medical adviser was quite detailed and was incorporated into the authority's decision, in the following terms:

\section{DEPRESSION/SUICIDAL THOUGHTS}

The applicant suffers from depression according to his GP, but this has been treated at low level with amitriptyline alone, a minor and outdated antidepressant drug which has largely been superseded in modern clinical practice.

His condition has not been such as to necessitate referral to a psychiatric hospital or specialist psychiatrist, nor to be admitted to a psychiatric unit, and his condition is clearly not psychotic or severe in nature, as this would have necessitated greater or multiple drug treatment or psychiatric referral.

I note Dr Sultan's assertion that he is at risk of suicide particularly if made homeless, but this is not borne out by the reports from the psychologist who is in regular therapeutic contact with the applicant....

I also consider the risk of self-harm low given Dr Sultan's decision to prescribe him with Temazepam, a well known sleeping drug which is toxic in overdose and responsible for a significant proportion of all pharmacological self harm throughout the UK.

Bellouti indicates that having a basis for refuting the applicant's evidence put before the authority seems key in deciding whether medical evidence from the applicant can effectively be rejected. This is further illustrated in the contrasting decisions reached in two cases heard together and involving the same local authority: Hall v. Wandsworth L.B.C.; Carter v. Wandsworth L.B.C. [2004] EWCA Civ 1740; [2005] H.L.R. 23. In the former the applicant's GP had written:

Clearly Mr Hall has a history of serious mental illness and my concern is that if his depression worsens he may develop another episode of acute psychosis. He does not have a good track record of accepting help for his mental health, and so it is likely that he may require sectioning at some stage. He is also at risk of developing further alcohol dependence, therefore in such circumstances he would not be able to fend for himself and would certainly suffer detriment.

The decision of the authority summarised the advice from the medical adviser which stated:

His previous mental illness is noted which led to breakdown in 1985 and 1999. However of late his depression is considered of much less severity and he has declined any treatment. It is no longer considered psychotic in nature, nor such 
as to impede normal activity and function...No housing recommendations. There is nothing to materially hinder his ability to cope as a homeless person.

The latter was held to be advice on which the reviewing officer was entitled to rely.

By contrast in Carter the view of the medical adviser was not referred to in the decision letter. Mrs Carter's GP's view set out in a letter was accepted as 'fully comprehensive and provides a good profile of your medical history and functional abilities, without further enquiries being made.' That letter, however, also expressed the view that 'It is undoubtedly clear that Ms Carter is a very vulnerable person' - which was taken by the court to refer to the Dr's opinion on her depression and the likelihood of deterioration. Notwithstanding this, the authority concluded that the applicant was not vulnerable. As no substantive reason was given for rejecting the view, the decision was defective.

An even stronger example is given in Lumley, where the medical adviser simply ticked a box which stated that the applicant was not vulnerable, and gave no reasons for rejecting the views of Mr Lumley's G.P. This was clearly inadequate.

One of the common threads for the later cases is the use of one 'private' company, which provides the medical assessments: NowMedical. Their website (http://www.nowmedical.co.uk/) used to boast that they provide services to over 50 local authorities in the UK. Figure 1, taken from the web-site in July 2007, gives an indication of the service they are offering in assessing vulnerability.

\section{Figure 1: NowMedical Website}

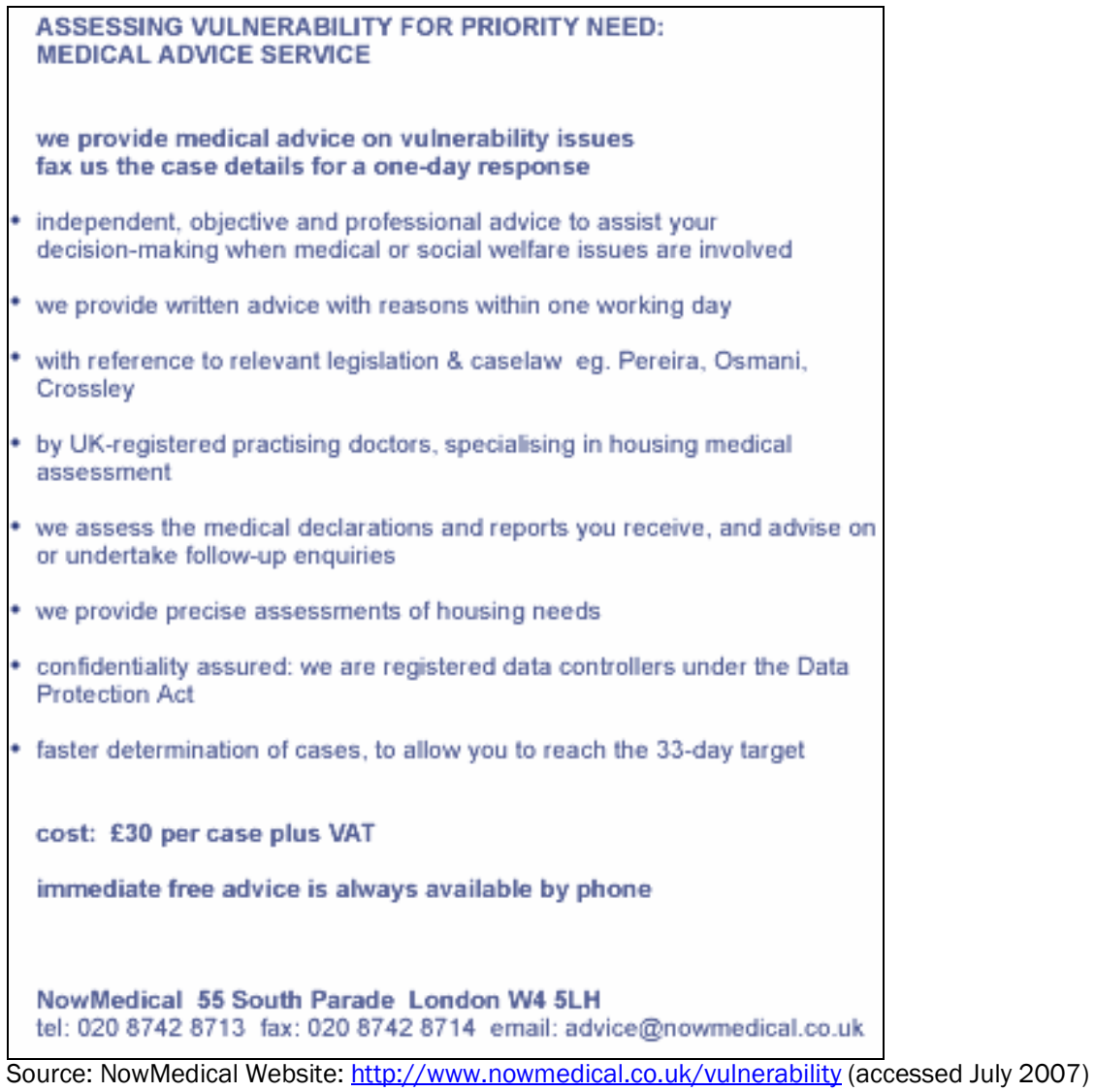


In general, they do not meet the applicants and simply give an opinion based on the written evidence that the authority has. There have been suggestions made that central Government has been pushing local authorities into using this company in order to reduce the numbers of homeless applicants. They certainly have a reputation for denying claims of vulnerability (Marshall, 2007). The concerns were sufficient for questions to be raised in Parliament in 2006 about the role of NowMedical, and whether their use had been encouraged (Hansard, 2006).

The response from the Minister was incredibly non-committal, making no reference to the particular firm but blandly stating:

.... In cases where the applicant may have a priority need because of vulnerability due to a medical condition, the authority, may wish to seek a specialist medical opinion to help inform their decision, and should have regard to any medical or social services advice obtained. We have no plans to commission research into the accuracy of such advice at present.

Officials in the Homelessness and Housing Support Directorate work with local authorities to encourage good practice on preventing and administering homelessness. This includes sharing information on a wide range of specialist advisory services which other authorities have found useful. In providing this factual information, officials are advised to avoid making recommendations of any kind, and to stress that it is for authorities to decide which services to use and which providers to employ....

Although, given the Government stance, there is no research on the use of NowMedical, there is some anecdotal evidence from homelessness officers that they have been encouraged to use it, on the basis that it will bring consistency of decisionmaking. That it may also reduce acceptances is illustrated by the following report from Broadland D.C., updating their homelessness position at the end of 2004-05:

Other more general initiatives, such as the Nowmedical service which enables officers to get professional medical advice on their clients, have also been very effective in reducing homeless acceptances.

In a number of the cases discussed above, those representing applicants have sought to attack the use of NowMedical as a basis for decision-making about the medical state and vulnerability of applicants. In none of the cases did the courts accept that the use of NowMedical could be inappropriate. In two more recent cases, however, the position has begun to shift. First in Khelassi v. Brent L.B.C. [2006] EWCA Civ 1825, a psychiatric report was provided in relation to Mr Khelassi. This stated:

He presents with psychological difficulties currently which in my view amount to difficulties with anxiety. He is in my view substantially depressed. Also he presents with difficulties which in my opinion would be consistent with being a current partial syndrome of post traumatic stress disorder.

This gentleman describes frequent suicidal thoughts and in my view there is a real and substantial risk of him killing himself (I have assessed the risk of suicide in many thousands of patients). It is my view that he urgently requires to be under the care of a local community mental health team who could provide him with psychological support and further treatment. 
This report was sent to NowMedical, whose Dr Keen concluded that Mr Khelassi was suffering from reactive depression, caused by his wife leaving him and concluded that:

I note in detail Dr Steadman's report which is a one-off 'snapshot' produced for legal purposes; he is not actively involved in treating this case. However, it is clear from the report that he does not consider any mental illness to be severe in nature and broadly supports my view above.

In summary, I do not believe that any depression is such as to significantly impede the applicant's normal and reasonable function, nor will materially hinder his ability to cope as a homeless person, and I do not consider that there is a significant risk to his health by homelessness. I therefore continue to make no housing recommendations.

Both in the lower court and in the Court of Appeal, the judges pointed out how Dr Keen's report failed to refer to the suicidal tendencies, and could not understand how Dr Keen concluded that Dr Steadman's report supported his view that the depression was not severe. Further reports were submitted to the authority which reiterated $\mathrm{Mr}$ Khelassi's suicidal thoughts. Dr Keen was commissioned to examine Mr Khelassi. His conclusions were set out in a further report:

I examined the applicant...and have carefully reviewed the file and various medical reports; my assessment concurs broadly with Dr Steadman's in that I found him to be depressed, to a moderate extent (Becks score 24). I found no definite psychotic systems and whilst he has thoughts of self-harm, there is no actual suicidal intent...

Overall I do not consider his depression of a type or severity such as to significantly impede his reasonable function, nor do I see material risk to his health from homelessness, and I therefore do not consider him vulnerable on any medical grounds.

The final decision letter relied heavily on this advice. The decision was quashed at first instance because the authority had failed to reconcile the differences between the views of Dr Keen and those of Dr Steadman. The Court of Appeal refused permission for the authority to appeal, saying that the judge's decision was 'plainly right.'

Secondly, the Court of Appeal further considered a case where the views of NowMedical had been relied upon in Shala v. Birmingham C.C. [2007] EWCA Civ 624. This is the most detailed review yet by the Court of Appeal of the practices of NowMedical, and is extremely critical. Again the applicants were refugees, who during the Kosovan war had lost contact with three of their daughters and had no knowledge of what had become of them. Mrs Shala suffered from depression and PTSD, for which she was in receipt of prescribed medication. Dr Keen was sent various medical reports which were provided by the applicants' solicitors. He concluded that her symptoms were not severe and there was no basis for provided her with housing. The Court of Appeal quashed the decision of the local authority, first on the ground that they had failed properly to take into account later reports which were provided after Dr Keen had made his recommendation.

More interestingly, the Court also considered the weight to be given Dr Keen's advice by the local authority. This was described in the authority's decision letter as 'impartial.' This is described by the Court of Appeal as 'unfortunate' (para 16): 
The pointed reference to Dr Keen's view as 'impartial', suggesting that the views of [Mrs Shala's doctors] might not be, is most unfortunate. In the light of it, it was particularly important that the remark in Dr Keen's second report that 'there is no particular assertion of severity' should be matched with great care against the terms of the reports on which he was commenting: 'very depressed'; 'severe posttraumatic stress disorder'; 'high dose anti-depressants'. No attempt is made to do this: instead Dr Keen's is treated as a dependable opinion, albeit he has never examined Mrs Shala or discussed her case with a doctor who has...

From this the Court of Appeal concluded that the authority had not approached the decision in an appropriately fair-minded manner. The Court of Appeal then went on to consider the proper use of medical advisers. There could only be a limited role for such advice. Referring to his role in the Khelassi case the Court of Appeal commented (para. 22):

Dr Keen is not a psychiatrist, with the result that the county court judge had been fully entitled to regard his dismissive comments on a qualified psychiatrist's report insufficiently authoritative for the local authority to rely on. In this situation a local authority weighing his comments against the report of a qualified psychiatrist must not fall into the trap of thinking that it is comparing like with like. His advice has the function of enabling the authority to understand the medical issues and to evaluate for itself the expert evidence placed before it. Absent an examination of the patient, his advice cannot itself ordinarily constitute expert evidence of the applicant's condition.

Such an approach may make it more difficult in the future for authorities simply to dismiss the evidence from an applicant's doctors on the basis of a $£ 30$ report from NowMedical. Since the decision in Khelassi, NowMedical have started to offer reports from psychiatrists ${ }^{1}$, whether these can constitute 'expert evidence' without an examination of the patient will no doubt be challenged in a future case.

\section{Conclusions}

What emerges from this study of the court decisions relating to vulnerability is the way that local authorities have tried to limit their duties to those with mental health problems. The courts have generally been willing to uphold such an approach. Thus they have left it to local authorities to decide what level of risk of harm is required in order for an applicant to qualify as vulnerable. While suicidal ideation seems to provide some sort of point of significance, if there is evidence suggesting it will not be acted out (even if conflicting) this can be used to deny assistance. Further there is an assumption that a degree of depression, and (particularly amongst refugees) PTSD is the norm for the homeless and that this therefore cannot be used to differentiate them in the necessary way to gain assistance.

The Shala case has rather belatedly raised a number of questions about how local authorities assess the medical evidence that is before them. Until that decision it appeared that authorities could take the views of NowMedical as 'trumping' those provided by doctors who had examined and treated the applicant. Authorities in the light of this decision will now have to be more circumspect with how they deal with medical evidence. Where medical evidence provided by the applicant relates to a mental health condition if the seriousness of it is to be denied, the authority will have to obtain their own equivalent from someone with the necessary expertise - a cheap $£ 30$ report from someone who has never met the applicant will no longer be able to be 
regarded as 'expert'. Authorities will also have to ensure that staff, in considering the evidence before them, understand the role that medical evidence and advice plays in the decision-making process. It would certainly seem to be the case that authorities often simply 'rubber stamp' the views of their own medical 'expert'. Homelessness officers must take back the decision of deciding whether an applicant is vulnerable. In doing so it is for them to weigh up the medical evidence before them, to understand its value. Training for homelessness officers is often limited (Cowan, 1997); if the process of assessing the vulnerability of the mentally ill is to be carried out lawfully authorities must address the knowledge and skills of their own staff.

\section{Notes}

1 At $£ 50$ rather than $£ 30$ : see http://www.nowmedical.co.uk/vulnerability.html, last accessed January 8, 2008.

* Correspondence Address: Caroline Hunter, School of Law, University of Manchester, Oxford Road, Manchester, M13 9PL, UK. Email: Caroline.Hunter@manchester.ac.uk.

\section{References}

Arden A., Hunter C., and Johnson, L. (2006) Homelessness and Allocations (7th Edition). London: Legal Action Group.

Cowan D. (1997) Homelessness: The (In-)Appropriate Applicant. Dartmouth Publishing: Aldershot.

Department for Communities and Local Government (2007a) Communities and Local Government Statistical Release 2007/0109: Statutory Homelessness, First Quarter 2007, England. http://www.communities.gov.uk/index.asp?id=1002882 \&PressNoticelD=2438 (last accessed June 22, 2007)

DCLG (2007b) Homelessness Statistics September 2007 and Rough Sleeping -10 Years on from the Target Policy Briefing 20. London: DCLG.

DCLG (2007c) Housing Live Tables on Homelessness, Table 627 http://www.communities.gov.uk/documents/housing/xls/141758 (last accessed October 12, 2007). London: DCLG.

DCLG (2007d) Housing Live Tables on Homelessness, Table 632 http://www.communities.gov.uk/documents/housing/xls/141758 (last accessed October 1, 2007). London: DCLG.

Hansard, (2006) 20 April, 2006: Column 801W.

Marshall T. (2007) ‘Bad Medicine.' Roof, November/December 2007, 35-38.

Watchman P. and Robson P. (1981) 'Homelessness Persons Obstacle Race.' Journal of Social Welfare Law, 1-15 \& 67-82. 